\title{
The three-dimensional lattice as an architectural space
}

\author{
Andrey Bolshakovi,* \\ ${ }^{1}$ Irkutsk National Research Technical University, 664074, Lermontova str., 83, Irkutsk, Russia
}

\begin{abstract}
Space is the main material with which the architect works. The space organized by the means of architecture is an art environment for the life of society. With many aspects of the organization of space, which are studied in the literature, the problem of their assembly and integration remains unsolved. The paper proposes a method of assembling spatial representations in architecture-the correlation of the spatial lattice and the factors of its form-formation, considered in the system, i.e. together. The approach is that in a broad overview of the world architecture, both in its theory and in practice, from historical to modern, examples of modification of spatial grids under the influence of one or a group of dominant factors are revealed. As a result, provisions on the relationship of the geometry of spatial grids with the following factors have been revealed: publicity and privacy; architectonics, the influence of the lattice on the differentiation of the streams of human movement; the architecture's ability to carry a message; navigation properties, evaluation of connectivity and centrality of places in the spatial lattice; evaluation of the quality of the composition through the identification of ways of order and randomness in the elements of the spatial lattice. The results of the work can be used both for theoretical understanding of the architectural space in the study and design of architecture, and in architectural education.
\end{abstract}

\section{Introduction}

Despite the fact that space is the central category of architectural thinking, there is no single universally recognized and competitive model of architectural space, which would take into account both the geometry of architecture and the social, cultural, and landscape factors of this geometry. Knowledge of the architectural space have been developed by many researchers. Alexander G. Gabrichevskii [8] proposed a heuristic model of space in the form of a pair of interconnected mass-void quantities. Mass is the dense building structures. Void is the rooms and their parts in terms of the building. As the basis of the theory of modern architectural composition, some works are very well-known, such as by Y. Chernikhov [16], K. Malevich, and E. Lisitsky. B. Hiller [22] founded and developed a theory of spatial syntax, the main tool of which is the graph theory and its application to the analysis of connectivity and centrality of street networks. Elena G. Lapshina [13] proposed the concept of a dynamic architectural space, the strength of which is the recognition of

\footnotetext{
*Corresponding author: andreybolsh@yandex.ru
} 
movement as the most important factor in the formation of architectural space. Mikhail V. Shubenkov [17] gave a broad overview of works on the architectural space, the main focus of which was parametric modeling. The practice of parametric modeling as the basis of architectural design was most clearly manifested in the works of Zaha Hadid [23]. Some theoretical generalizations of this experience were made by Schumacher [28].

Christopher Alexander [1] considered the spatial situations of a building and a city as templates and gave them a systematic description. Camillo Zite writes about the artistic significance of the archi-textural space. Social factors of architectural and town-planning design are studied by Z. N. Yargina and A. V. Krasheninnikov [11]. The landscape factors of the formation of the urban space were studied by Jan McHarg [25], Valery A. Nefedov, Ellina Krasilnikova, and the author of this work [3, 4]. I am also interested in the problem of modeling the architectural space, taking into account many factors that affect this space.

The purpose of this work is to systematize and generalize the fragmentary approaches to modeling the architectural space by relating the geometry of the spatial grid to the social, technical, environmental, and artistic factors of the architectural environment. The subject of the research is the properties of the architectural space as a result of the implementation of humanitarian needs.

The novelty of this research is that for the first time important but disconnected provisions of theory and practice of architecture are linked in the spatial lattice as a universal model of architectural space in a single system. A regularity has been revealed for the first time, showing the dependence of the directions of the modification of the spatial lattice on the factors of the architectural environment.

\section{Materials and methods}

The material of the work was the experience of domestic and foreign architecture, both historical and modern. The method of research is the correlation of geometric properties of architecture and socio-cultural factors that affect its geometry.

\section{Results}

A chain of interrelated provisions that reveal the creation and transformation of the spatial lattice as the essential basis of the scientific subject of architecture.

1. Architecture arises as a room, as a cell of an artificial environment, fenced from the outside world. The location, or habitat, regardless of size, whether it is a house or a city, is an artificial environment for the life of a person. The first rooms were menhirs and dolmens. Polar in weight in relation to them is an example of the Mongolian yurt, which weighs only $250 \mathrm{~kg}$.

1.1. Emptiness and mass. The room is an emptiness, the habitat of a person or a social group (family); and the shell, by means of which the cell is detached from the outer space, is a dense body. More precisely, these are walls, other supporting structures, overlap, and cover. According to A. G. Gabrichevsky [8], the first necessary model of architectural space is the dialectical unity of mass and emptiness.

1.2. Private and public space. The cell can be designed for both private processes and public. The privacy is correlated with the small size of the cell (house) $(6 \times 6,12 X 12)$. The public cell is associated with a large-span overlap (18x18 and over) and, as a rule, is called a hall. Publicity and equity is also embodied in the number and manner of entries in the cell. For an apartment and a house it is an entrance hall. For the public hall, this is the lobby, the entrance group of rooms. Confidentiality is in the traditional Yemeni apartment building. The socio-cultural zoning of the Russian hut is presented in Figure 1. 


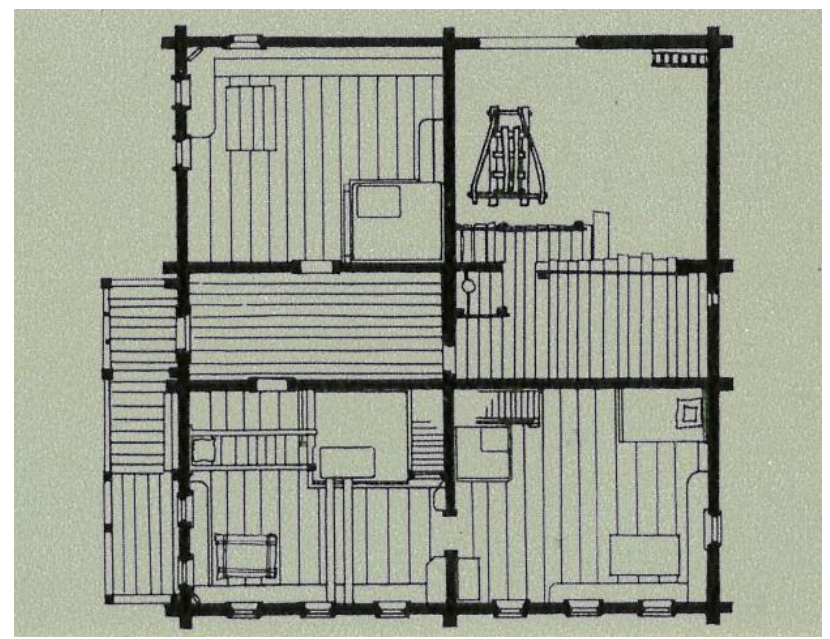

Fig. 1. Cells of a residential Russian house in the Arkhangelsk region (according to A. V. Opolovnikov).

2. Architecture and field. The architectural object is in the continuity space. The bodies are discrete, and the field is continuous. At each point of continuous space, we can establish the action of some force or quantity of interest to us. For example, each point of the atmosphere is characterized by the illumination, or the force and direction of the wind. That is, the quantities can be scalar and vector (having a directional action in space). Continuity and the gradient of properties are the main characteristics of the field. The potential (force) of the field decreases with the distance from the center of the force and with a decrease in its mass. Some fields can be infinitely extended. For example, the force of gravity.

2.1. Architectonics. Architecture in the field of gravity. Classical architecture is called the art of resistance to gravity. In the gravity field, it is basically difficult to create a fenced emptiness (cell). Overlapping, representing a great burden in itself, and even carrying a load, does not fall down and does not collapse the void only because special architectural conditions have been created-sufficient and necessary properties of support structures-walls and skeleton, as well as the geometry of the overturns. The columns of the Parthenon have enthasis, which is the widening to the lower third of the column, as well as the main beams (architrave) and second-power (triglyphs). Architectonics, unlike engineering design, not only assigns the necessary cross-sections, but also shows how the form works, resisting the arising load. So, in the temple construction, the expansion from the domes and arches, the masters translate into the geometric properties of these constructions, arkbutans, buttresses appear. In the cross-domed Orthodox church, the passage from the dome to the drum, from the drum to the ring, then under the sail ring, and finally, the cylindrical vaults show the system of form conjugations that embody the architectonics in this type of buildings (Figure 2). In contemporary architecture, Santiago Calatrava [10] shows the art of architectonics in modern architectural forms, cable-stayed bridges, shells, in modern treatment of supports. In architectonics, they show who carries whom and what geometric properties the bearing and bearing elements.

2.2. Architecture in the field of action. Dynamic flows. Each cell is characterized by a certain functional or environmental resource. A person experiences the need to use different resources and environmental conditions in his/her activity. Accordingly, the consumer moves from one point (cell) to another. Being in the room, a person circulates inside the cell, because the room is equipped with furniture or production equipment, the use of which 
is characterized by a cycle during the day. When moving from one cell to another, keeping the path from one area to another, a person or social group commits a movement. Stepping, easy or extreme pedestrian accessibility allowed A. V. Krasheninnikov [11] to highlight the micro-, meso-, and macrospaces of pedestrian activity as special social-town-planning units in the city. The city square is attractive with a certain geometry and space equipment [5]. We can say that the field of action in the architecture is determined by the movement (circulation or movement), its intensity, flows, direction, distribution of current. From the point of view of space development, a person uses his kinesthetic sensations and abilities for locomotion and synergy (types of motor acts), according to N. A. Bernstein [2] and Ye. G. Lapshina [13]. Architecture by its form and system of connections creates conditions for the optimization of movement. This is called ergonomics at the level of room, building. and logistics at the city level (Bill Hiller, spatial syntax).
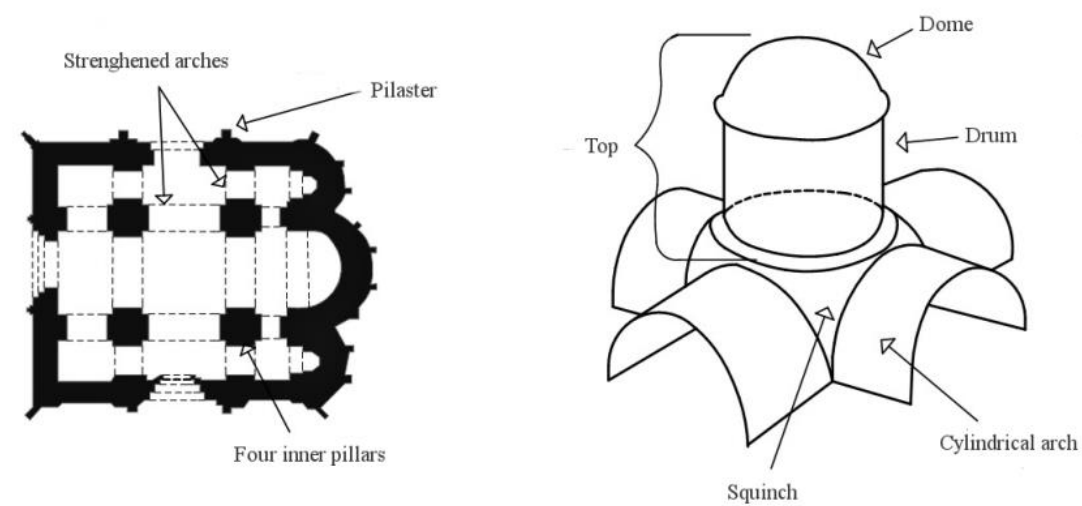

Fig. 2. Transfer of the rasp from the dome through the vaults to the walls and columns in the crossdomed Orthodox church.

2.3. Architecture and the field of information. The information field in the architectural and town-building aspect is the cognitive properties of architecture, as well as the ability of architecture to carry and interpret philosophical, scientific or socio-cultural messages. The architecture bears messages about the appointment, cultural significance, constructive and engineering basis of the building, reaction to climate, lifestyle, material prosperity, size of function. The composition plays an important role in the information potential of architecture. As well as innovative ideas of natural science and engineering. In Russianlanguage literature, Ingvar Strautmanis (1978) raised the question of the informational component of the architecture for the first time [15]. Such a mathematical idea as the continuity of the transition of the inner to the outer by the example of the Möbius strip, was first started in the architecture by Peter Eisenman in his project Reinhardt House in Berlin (Moebius House). The topic was picked up by Chris Prechtec in the expansion project of the Austrian National Library in Vienna [26] and then Chao Weiping, chief architect of the Beijing Institute of Architectural Design [27] Weiping designed the international media center "Phoenix" in Beijing. In both projects, the spatial idea was the Möbius band. The interaction of external and internal space in architecture is an important topic in which architecture shows the possibilities of interpreting mathematical and topological ideas.

3. Cell and communication. Cells and halls need a lot, they are densely packed in a large building. The set of cells forms a space lattice. Cells cannot exist without communication with the outside world and with each other. Communication is carried out through the communication system of the building, or through the city's transport and pedestrian street 
network. As a link system in the building stands an entrance hall, a staircase in the sectional building, a corridor or gallery, an atrium, a passage. The main (arteries) and local (capillaries) can be distinguished in the network of streets.

An important consequence of solving the problems of communication between cells with each other and with the external space is navigation. Architecture should help people to orient themselves in space. So, the Russian temple towers are above residential development and located at the crossroads of important roads, helping people to navigate in the city and in the countries of the world. Because the altar is facing East. The same function is for mosques in the Muslim city, which is only more binding and rigidly orienting. Any mosque' qiblah looks in the direction of Mecca [7].

The cell links (input-output, window opening, balcony-loggia-gallery) make it valent for interaction with other cells. "Monovalent" cells of rooms or apartments are connected with a corridor or with a landing of a staircase. The same cells can reach the atrium, or the courtyard. In these cases, the only input makes the cell, first, private, and, second, subordinates its location to the communication on which the cell is strung. Multivalent cells (for example, the lobby) are pierced with many paths, and they represent a distribution node in which a lot of communication axes converge, and in many respects determine the layout of the building.

The Star square in Paris draws eleven streets into itself, and it is an important spatial node that determines the architectural and planning structure, or the city's street network, at a great attraction [6].

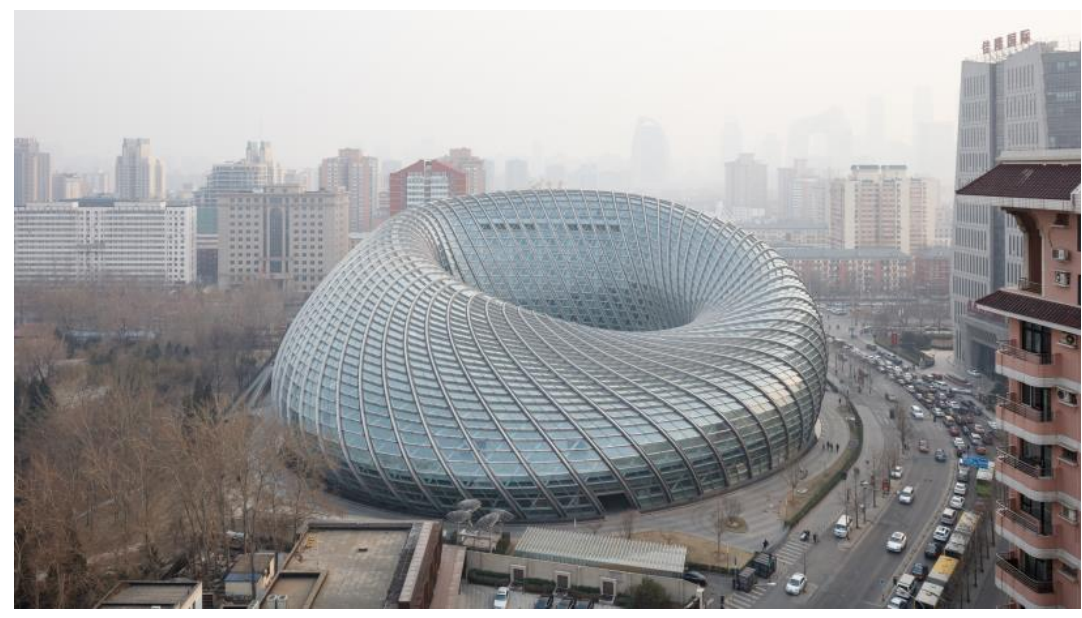

Fig. 3. The International Media Center "Phoenix" in Beijing (Chao Weiping). The idea of the Mobius strip is embodied by the perametric modification of the cells of the shell of a building.

3.1. Spatial gratings. The law of lattice shaping is as follows. 1) The primary cell is the base element. This can be a cube, for example. 2) Next, the process of copying cubes should be started. 3) Parallel process-transformation of cubes according to a certain algorithm: increase or decrease in dimensions, change angles, under which the faces of cells intersect. Cubes are transformed into prisms, truncated pyramids, and irregular geometric bodies. 4) The process of transformation of cells is accompanied by their movement in space. Cells change the location and are located along those directing straight or curved lines that can be communications, silhouette lines, or can be directing nonlinear rotation bodies. In any case, the cells are tightly packed or assembled compactly. As a result, the shape of the building tends to the fact what Antonio Gaudí and Rudolf Steiner did. It should be emphasized that the modified cells are stacked in the body of the spatial lattice so that the gradient of the changes is continuous. Algorithms for the formation of spatial lattices in 
a nonlinear architecture are often written in the corresponding computer programs, i.e. scripts.

This method of obtaining spatial gratings was called parametric modeling, or design. And widely and successfully used in the works of Zaha Hadid [23]. The famous work of Frank Gerry, the Guggenheim Museum in Bilbao, Spain, is also a spatial lattice.

3.2. Architectural composition. In the architectural composition is important not only the intuition of the artist. The architectural composition has a rational basis. First, architectural composition always means order. With respect to the spatial lattice- (he objective geometric basis of the architectural form), this means that there are rules by which this lattice is constructed. That is, the composition is based on the order, i.e. the set of rules for constructing the form. Secondly, a simple order, for example, a notebook in a cage, or a spatial lattice consisting of identical cubes, densely packed one on top of another, or builtin between columns and beams, which are located at the same step, is difficult to talk about composition. The Khrushchovki in their time were deprived of such excess as an architectural art composition. Third, there must be at least two geometric themes in the spatial lattice, which differ from each other or are in contradiction according to the principle of pattern formation, if they are treated separately.

The art of architectural composition is to be able to combine two (or more) different basic elements (for example, a curved element and a rectangular lattice) into a single system. In this case, the curvilinear spot is superposed on a rectangular lattice. It is necessary to create seams between the specified figures on the boundaries of their conjugation. Elements of the seam, while they will have the properties of both curved spots and rectangular cells.

Chaos is not a composition. It's noise. All the elements are different and the connections between them are different. However, if, for example, we apply the rule of geometric similarity to each of the elements of the set of "chaos" and construct exactly the same figures, but proportionally changed, around the boundaries of chaotic figures, then we again get a composition in which there is, as the maximum variety, and clearly readable order. Repeating randomness creates order. Approximately this principle of constructing the composition was applied on the basis of the Voronoi-Dirichlet decomposition [14] (see Figure 4).

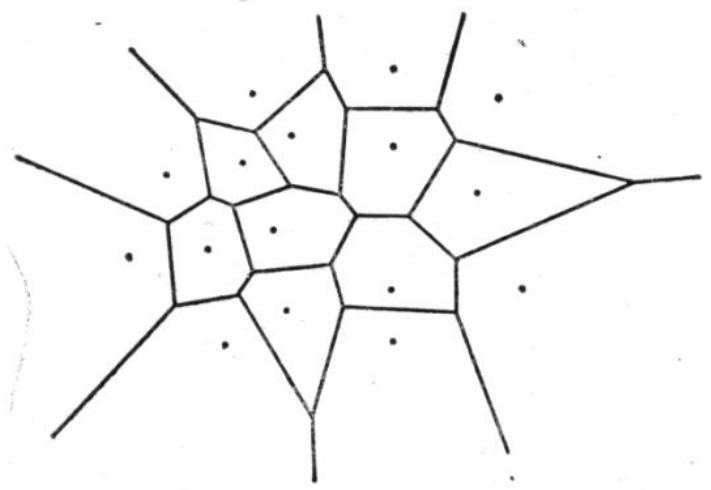

Fig. 4. The Voronoi-Dirichlet breakdown.

The essence of the partition (flat lattice) is as follows: 1) An arbitrary set of points is applied to the plane. They are all at different and random distances from each other. 2) Among the set of points, those points that are closer to each other are pairwise grouped. These pairs of points are connected by straight lines. Then these segments are divided in 
half. And in the middle of this segment, the perpendicular is restored to it. 3) Perpendiculars constructed for all adjacent points are connected to each other. As a result of these constructions, a complex flat lattice arises, or, more correctly, a network possessing the property of both great diversity and a completely subtle order. This method (the Voronoi-Dirichlet splitting) was used by the Swiss architects Jacques Herzog and Pierre de Meuron [18] who designed the Olympic stadium in Beijing, called the Eagle's Nest (see Figure 5).

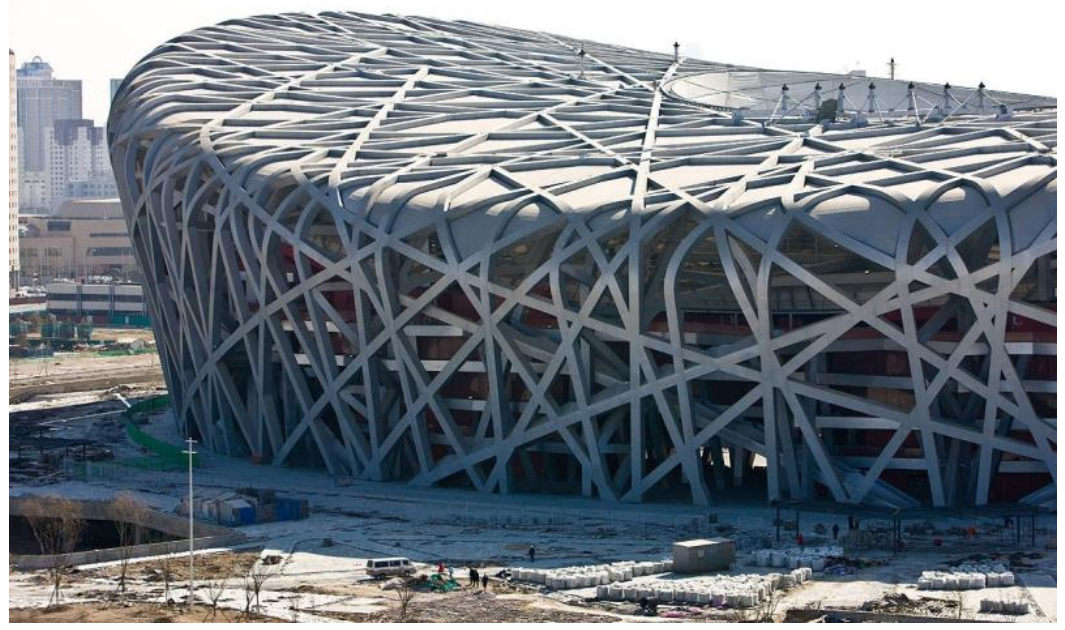

Fig. 5. The Olympic Stadium in Beijing, designed with the Voronoi-Dirichlet's idea (Jacques Herzog and Pierre de Meuron), 2008.

3.3. Architectural topology. Architecture is created so that the person in it can move (see the section 2.2.) The movements should be as long as necessary. We need to save the energy of the human movement when carrying out certain actions-in everyday life, at work, at leisure. Movements connect one cell to the other. The connectivity of architectural spaces is one of the necessary conditions for the effectiveness of architecture. If the cell with the input (inputs) is represented as a node, and the communication network: corridors, galleries, as the edges connecting these nodes, we get the network graph, which is the main topology tool. For a given network of streets, traffic from all locations to all destinations is maximized on the central segments of the streets [19, 22].

The presence of a contact or lack of contact is the reason why the network is working or not working. This applies to electrical networks, social networks, architectural, and urban networks. It is clear that if through the bedroom to break through another entrance to the kitchen, it can only be the so-called "studio," which is unsuitable even for a nuclear family: two parents and a child. If the bedroom is to join the wall of the staircase, we will break the silence in the bedroom. If the natural skeleton of the city (a network of river and stream valleys) is combined with the transport highways, then we would destroy the natural and recreational skeleton of the city. If a skyscraper is placed next to a wooden one-story architectural monument, this will be a dissonant contact. And so on.

Connectivity is manifested in the structure of the communication structure of the building. A classic example of a topologically oriented architecture is the solution of the question of how to organize the connections between inner spaces and outer space. This question is solved with dignity in such a morphotype as an atrium house. The Greek megaron is a type of apartment house with an atrium, in the center of which is a hearth, and 
the entrance to the building is through a buffer space, a portico. Megaron is a classical topological scheme of the connection between the internal and external space of the house. From the analysis and generalization of the above three points, the following formula of the architectural lattice.

\section{Conclusion}

The formula of a multidimensional lattice as an architectural space.

In the modification of the cells and the relationships of the spatial lattice under the influence of the shaping factors, we distinguish five main functions, or dependencies.

Function 1. Cell and communication. The geometric shape of the lattice is a function of: (a) the number, size (cell or hall), and the configuration of cells; (b) forms and degree of connectivity of cells through corridors, streets, squares, stairs, atriums, vestibules, passages, galleries; (c) rules for building a silhouette, a facade, a building plan (smooth compact, amplitude with a developed perimeter); (d) the degree of following the town planning plan for the sections of the crossed relief.

Function 2. Privacy and publicity. Dependence of the geometric shape of the lattice on (a) the factor of publicity of premises, planning elements; (b) the factor of privacy of premises, planning elements.

Function 3. The fields of gravity, motion, information. Dependence of the geometric shape of the lattice: (a) the factor of the effect of gravity on the architectural design of the building; (b) the factor of the dynamics of pedestrian flows, their distribution, the degree of centrality; (c) dependence acts both in the direction of increasing the network connectivity and establishing discontinuities and non-rational cell contacts.

Function 4. Quality of the composition. The quality of the composition depends on the combination of: (a) orderliness, rules for constructing a spatial lattice of modifiable cells; (b) degrees of mastering random locations, configurations and partitions in the resulting spatial lattice of an architectural object.

Function 5. Architecture and landscape. The shape and location of the multidimensional lattice depends on the properties of the landscape locations; (a) elements of emptiness: green recreation, squares, parks, embankment boulevards are timed to valleys, thalwegs, floodplains, soles of hills [25]; (b) elements of mass depend on the location and properties of sublime (eluvial) elements; (c) geometry of the relief affects the spatial and spatial solution of the architectural object; (d) for the placement of construction on the territory under the building choose the worst plot, the best part is saved as a landscape environment [1].

All five functions, expressed at the subsequent stage of the investigation in the formulas, form a system.

The root of the solution of the system of equations must be the parameters of the cells and the configuration of those links that unite them. Knowledge and skills for the wellfounded formation of spatial grids serve as the basis for the competence of architectural education.

\section{References}

1. K. Alexander, S. Ishikawa, M. Silverstein, Template language: cities, buildings, construction (Art. Lebedev Publishing House, 2014)

2. V. P. Zinchenko, N. A. Bernshtein, Biomechanics and Physiology of Movements (Publishing house "Institute of Practical Psychology", Moscow, NGO "MODEK", Voronezh, 1997) 
3. A. G. Bolshakov, Urban planning organization of the landscape as a factor of sustainable territory development (Irkutsk, 2003)

4. A. G. Bolshakov, Fundamentals of the theory of urban planning and district planning (ISTU, Irkutsk, 2004)

5. A. G. Bolshakov, A. A. Anufriev, Herald of Civil Engineers, 5, 5-17 (2015)

6. A. G. Bolshakov, Topology of Belgorod (Irkutsk National Research Technical University, Irkutsk, 2017)

7. A. G. Bolshakov, Architecture and Construction of Russia, 4, 30-37 (2016)

8. A. G. Gabricheskii, Morphology of Art (Agraf, Moscow, 2002)

9. G. Zeytun, Organization of internal structure of projected architectural systems (Stroyizdat, Moscow, 1984)

10. S. Kalatrava, Buildings and Bridges (All-Russian Museum of Decorative and Applied and Folk Art, Moscow, 1994)

11. A. V. Krasheninnikov, Urban Development and Urban Environment (Open Science Publishing, North Carolina, 2017)

12. E. G. Lapshina, Architectural space as a dynamic system (NNGASU, Nizhny Novgorod, 2016)

13. A. V. Opolovnikov, Russian wooden architecture (Izd-vo Art, Moscow, 1983)

14. F. Preparata, M. Sheymos, Computational Geometry (Mir, Moscow, 1989)

15. I. A. Strautmanis, Informative and emotional potential of architecture (Stroiizdat, Moscow, 1978)

16. Ya. Chernikhov, Architectural fantasies. 101 composition in paints (http://science.total arch.com/book/1023.rar, 2017)

17. M. V. Shubenkov, Structural patterns of architectural shaping ("Architecture-S", Moscow, 2006)

18. Herzog \& de Meuron, Arch2O Editorial Team. Bird's Nest-Beijing Olympic Stadium (https://www.arch2o.com/birds-nest-beijing-olympic-stadium-herzog-de-meuron, 2018)

19. A. G. Bolshakov, Russian Journal of Building Construction and Architecture, 3(35), 66-79 (2017)

20. C. Janks, The architecture of the jumping universe. A polemic: how complexity science is changing architecture and culture (Jonh Willey \& Sons, Chichester, 1997)

21. P. Eisenman, Diagram Diaries; introduction By R.E. Somol (Universe Publishing, New York, 1999)

22. B. Hillier, Space is the Machine: A Configurational Theory of Architecture (Cambridge University Press, 1999)

23. Z. Hadid, Architects (http://www.zaha-hadid.com, 2018)

24. B. Lawson, The language of space (Reed Educational and Professional Publishing Ltd, Oxford, 2001)

25. L. McHarg Ian, Design with nature (Natural History Press, New York, 1971).

26. Chris Prechteck, The Spiraling Library - National Library of Austria Extension http://www.evolo.us/architecture/the-spiraling-library-national-library-of-austriaextension-chris-prechteck, 2017) 
27. J. Giovannini, Journal of the American Institute of Architects (http://www.architectmagazine.com/design/buildings/phoenix-international-mediacenter-designed-by-biad, 2014)

28. P. Shumacher, Hegemonic parametricism (http://www.patrikschumacher.com/Texts/ Hegemonic\%20Parametricism.html, 2016) 